\title{
Physical Activity and Balance Changes in Women with Urinary Incontinence: A Prospective Study
}

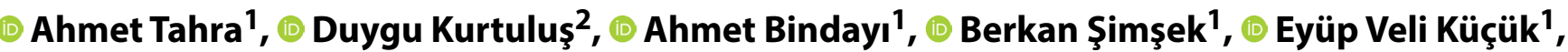 \\ Uğur Boylu' 1 \\ ${ }^{1}$ Department of Urology, Health Sciences University, Umraniye Training and Research Hospital, Istanbul, Turkey \\ ${ }^{2}$ Department of Physical Medicine and Rehabilitation, Health Sciences Univesity, Umraniye Training and Research Hospital, Istanbul, Turkey
}

\begin{abstract}
Introduction: The main purpose of this study is to compare the physical activity and balance, in patients with stress urinary incontinence,overactive bladder and control group, objectively and subjectively. Secondary purpose was to assess these findings in the terms of incontinence severity.

Methods: In this study, 14 patients with stress urinary incontinence and overactive bladder and 11 patients with no lower urinary tract symtpoms were included. Incontinence severity was evaluated with ICIQ-SF, IIQ-7, UDI-6, OAB-V8 forms subjectively and pad test objectively, physical activity were evaluated with IPAQ-SF and the form that we prepared for this study: "Avoidance of movement questionnaire". Balance was evaluated with stability index, open eye and closed eye test. Tineti gait and balance instrument, Berg balance scale, go and up test are also evaluated.

Results: Median age was 48 (39-68). In study group all domains of Qualtiy of Life (QoL) except physical role functioning were lower than control group. Physical activity level was significantly lower in study group. Median metabolic equivalent score (MET) was 697 (49-2400) in study group and 2100 (580-2900) in control group ( $p=0.001)$. The median "Avoidance of movement questionnaire" was 21.5 in study group and 16 in control group and it was statistically significant ( $p=0.004)$. Balance and gait was affected in study group compare to control group. Mean Tinetti score, Berg balance scale, go and up test, eyes open/eyes closed balance test were significantly low in study group but stabilometry test is equal in these two groups. Incontinence severity were not correlated with subjective and objecitve balance evaluation but we found correlation with Avoidance of movement questionnaire and incontinence severity in correlation analysis.

Discussion and Conclusion: Physical activity restriction, balance problem in tests and exam, imparied QoL score were found in patients with urinary incontinence compare to control group. Subjective and objective incontinence severity assesment and balance evaluation were not significicantly correlated.
\end{abstract}

Keywords: Balance; physical activity; urinary incontinence.

U rinary incontinence is a health problem that may impair the quality of life of the patients, cause additional morbidity by restricting their daily activities, and affect the patients both socially and economically especially with the use of diapers and pads. As is known daily regular physical activity effects the quality of life favourably, and decreases the incidence of accompanying diseases such as obesity and cardiac disorders ${ }^{[1]}$.

In the literature, the relationship between urinary incontinence and physical activity has not yet been clarified. Studies have shown that patients' physical activities are often restricted in conditions accompanied with urinary

Correspondence (iletişim): Ahmet Tahra, M.D. Saglik Bilimleri Universitesi, Umraniye Egitim ve Arastirma Hastanesi, Uroloji Anabilim Dali, Istanbul, Turkey

Phone (Telefon): +90546466 0346 E-mail (E-posta): ahmettahra@gmail.com

Submitted Date (Başvuru Tarihi): 13.05.2018 Accepted Date (Kabul Tarihi): 11.06.2018

Copyright 2018 Haydarpaşa Numune Medical Journal

This is an open access article under the CC BY-NC license (http://creativecommons.org/licenses/by-nc/4.0/). 
incontinence ${ }^{[2]}$. It has been observed that physical activity is increased in patients who received medical or surgical treatment and whose symptoms are cured ${ }^{[3]}$. However, the relationship between urinary incontinence and physical activity level and balance disorder is not clear. Current anatomic studies indicate that there is a close relationship between central control of balance and the bladder and spinal conduction pathways ${ }^{[4]}$. However, there is no study evaluating the relation between lower urinary tract symptoms and balance. There is also no study evaluating the change in physical activity and balance parameters after incontinence surgery.

The main purpose of this study is to evaluate physical activity and balance changes in stress and urge type urinary incontinence patients within the context of objective and subjective criteria. The secondary goal is to assess the relationship between these changes and urinary incontinence severity measures.

\section{Materials and Methods}

A total of 14 patients aged between 40 and 68 years who referred to outpatient clinic of our hospital between February 2016 and June 2016 including 12 women who underwent transobturator tape (TOT) surgery in our urology clinic and 2 patients who had overactive bladder disease (wet) were included in our prospectively designed study after approval of ethics committee of our hospital (date: 22.1.16, and registration \#: 1155), and informed consent forms of the patients were obtained.

Patients who had documented urinary tract infections, increased residual urine volume, neurogenic bladder dysfunction secondary to diabetic neuropathy or any other neurological disease, history of pregnancy or delivery within the last 6 months, severe arrhythmia or uncontrollable hypertension, asthma or advanced COPD, established diagnosis of cancer, incontinence surgery or cases that underwent gynecological surgery within the last 5 years, those with cognitive dysfunction, Parkinson's disease, dementia, multiple sclerosis or stroke which affect mobility of the person, previously experienced spinal cord injury, rheumatic diseases coursing with rheumatoid arthritis or ankylosing spondylitis, polio sequelae, hip and/or knee joint contracture, visual or hearing loss, vertigo, severe psychiatric disease (schizophrenia, major depression with, bipolar disorder or suicidal ideation), users of substance, opioid or narcotic analgesic were excluded from the study. Eleven female patients aged between 3356 years who did not have any complaints of lower urinary tract and met the above-mentioned exclusion criteria were selected as the control group.

For the subjective evaluation of urinary incontinence The International Consultation on Incontinence Questionnaire Short Form (ICIQ-SF), Incontinence Impact Questionnaire (IIQ-7), Urinary Distress Inventory (UDI-6) and Overactive Bladder Evaluation Form (OAB-V8) validated in Turkish severity (IPAQ-SF) and for the assessment of physical activity level International Physical Activity Questionnaire Short Form (IPAQ-SF) and "Avoidance of Movement Questionnaire" prepared by us (Table 1) were used. The Quality of Life Scale short form (QoLSF-36) was used to assess the quality of life of the patients.

For objective evaluation. 24-hour pad test and 72-hour

Table 1. Avoidance of movement questionnaire

To what extent do the following conditions disturb you?

I fear from wetting my underwears when

I exercise.

The people complaining of urinary leakage should not exercise.

I was leading a much more active life before the onset of this problem

I refrain from taking long walks because of my disease.

I want to make exercise, but I am afraid of worsening my disease.

I think that my disease keeps me from running.

Relaxing exercises as pilates, yoga, stretching Yes No make me wet my underwears.

I would do exercises if I were not incontinent. My disease prevents me from doing my daily routine/household chores/gardening activities. I used to do my regular exercises/sportive activities before onset of my disease.

I started to move more slowly because of my disease.

I am refraining from carrying heavy bags, objects or parcels because of my disease. I am trying not to dance, and jump with the fear of wetting my underwears.

I am refraining from pushing, pulling objects or changing the places of household goods.

I avoid doing floor exercises as pull-ups,

2

1

2

1

2

1

2

1

and push-ups.

I think that climbing, going up steep hills, and climbing stairs increase my complaints of urine leakage. 
voided urine volume schedules were applied. Assessments of patients' balance were made using the general stability index, eyes open/eyes closed balance tests, and Biodex Stability System (Biodex Medical Systems, Shirley, NY, USA). In addition, the Tinetti balance and gait test, the Berg Balance scale test, the up and go tests were applied.

The Mann- Whitney $U$ test was used to compare the independent changes between the patients with urinary incontinence and the control group. Fisher exact test was used to compare the qualitative variables. Multiple comparisons between groups were performed with post-hoc analysis. Pearson correlation test was used to evaluate the relationship between urinary incontinence and balance scores. In all statistical comparisons, $\mathrm{p}$ values smaller than 0.05 were considered to be significant.

\section{Results}

\section{i. Demographic Characteristics}

The median age of the patients was 48 (39-68) years. Patients' body mass indices (BMI) ranged from 21 to $38 \mathrm{~kg} /$ $\mathrm{m}^{2}$. (median: $29 \mathrm{~kg} / \mathrm{m}^{2}$ ). The demographic characteristics of the patient and control groups are summarized in Table 2. There was no statistically significant difference between the two groups in terms of age, number of births and cigarette use $(p<0.05)$. The patients urinated $5-13$ (median 6.5) times during daytime. The urinary incontinence severity measurement scores were also calculated. Median (range) ICIQ-SF (15 [9-21]), OAB-V8 (8.5 [0-16]), UDI-6 (12.5 [9-18]), and the IIQ-7 (13 [4-20]) scores were estimated as indicated.

\section{ii. Balance measurement and test results in the patient, and the control groups}

When the patient and control groups were compared in terms of balance scales, a significant difference between the two groups was found in terms of Tinetti balance and gait scale scores (Table 3 ). Balance tests were evaluated; and a significant difference between the groups as for eyes open/eyes closed balance test scores was observed, while any difference was not seen in terms of stability test results.

A correlation was not found between. The International Consultation of Incontinence Questionnaire-Short Form, Tinetti balance, and gait test and Berg balance scale scores. In comparisons between the ICIQ-SF score and the balance measurements, a significantly positive correlation was found only with the "eyes closed balance test" (Fig. 1). Table 4 summarizes the results of the correlation analysis
Table 2. Comparison of demographic characteristics of the patient, and the control groups

\begin{tabular}{lccc}
\hline & Patient & Control & p \\
\hline Patients $(\mathrm{n})$ & 14 & 11 & \\
Age & $50.5(40-68)$ & $47(39-58)$ & $0.22^{* *}$ \\
Parity & $2(1-5)$ & $2(0-3)$ & $0.158^{* *}$ \\
BMl $\left(\mathrm{kg} / \mathrm{m}^{2}\right)$ & $31(23-38)$ & $25(21-31)$ & $0.005^{* *}$ \\
Smokers $(\mathrm{n})$ & 4 & 4 & $1^{*}$ \\
Postmenopausal state & 8 & 2 & $0.09^{*}$ \\
\hline **
\end{tabular}

**Mann-Whitney $\mathrm{U}$ test; *Fisher's Exact Test; BMI: Body mass index.

Table 3. Balance measurement, and test results of the patient, and the control groups

\begin{tabular}{lccc}
\hline Group & Median & Min-Max & p \\
\hline $\begin{array}{l}\text { Tinetti scale } \\
\text { Patient } \\
\text { Control }\end{array}$ & 25 & $11-28$ & 0.001 \\
Berg scale & 28 & $26-29$ & \\
$\quad$ Patient & & & \\
Control & 51.5 & $38-56$ & 0.001 \\
Stabilometer test & 56 & $52-56$ & \\
Patient & & & \\
Control & 25.35 & $14.56-66$ & 0.06 \\
Eyes open & 66 & $10.45-82$ & \\
Patient & & & \\
Control & 97 & $24-146$ & 0.02 \\
Eyes closed & 173 & $28-277$ & \\
Patient & & & \\
Control & 88.5 & $10.27-170$ & 0.01 \\
Up and Go Test & 142.07 & $18-263$ & \\
Patient & & & \\
Control & 1 & $1-3$ & 0.01 \\
\hline
\end{tabular}

Table 4. Correlations between ICIQ-SF, and balance assessment tools

\begin{tabular}{lccc}
\hline $\begin{array}{l}\text { ICIQ-Sf vs } \\
\text { parametres }\end{array}$ & $\begin{array}{c}\text { R correlation } \\
\text { coefficient }\end{array}$ & $\begin{array}{c}\text { Confidence } \\
\text { interval (\%) }\end{array}$ & p \\
\hline Tinetti balance test & -.033 & $95 \mathrm{Cl}$ & 0.91 \\
Berg balance scale & -.075 & $95 \mathrm{Cl}$ & 0.79 \\
Eyes open balance test & -.293 & $95 \mathrm{Cl}$ & 0.30 \\
Stabilometer test & -.283 & $95 \mathrm{Cl}$ & 0.30 \\
Eyes closed balance test & -.541 & $95 \mathrm{Cl}$ & 0.04 \\
\hline
\end{tabular}

between ICIQ-SF and balance assessment tools.

Any correlation was not found in the correlation analysis performed between the pad test, and the balance assessment tests, device measurements. Table 5 summarizes the results of the correlation analysis performed between the pad test and the balance assessments. 
Table 5. Correlations between pad test, and balance assessment test results

\begin{tabular}{lccc}
\hline $\begin{array}{l}\text { Pad test vs. } \\
\text { parametre }\end{array}$ & $\begin{array}{c}\text { R correlation } \\
\text { coefficient }\end{array}$ & $\begin{array}{c}\text { Confidence } \\
\text { interval (\%) }\end{array}$ & p \\
\hline Tinetti balance test & -.033 & $95 \mathrm{Cl}$ & 0.91 \\
Berg balance scale & .129 & $95 \mathrm{Cl}$ & 0.66 \\
Eyes open balance test & .018 & $95 \mathrm{Cl}$ & 0.95 \\
Stabilometer test & -.107 & $95 \mathrm{Cl}$ & 0.71 \\
Eyes closed balance test & -.125 & $95 \mathrm{Cl}$ & 0.67 \\
\hline
\end{tabular}

\section{iii. Comparison between patient, and the control groups in terms of physical activity}

In the evaluation of physical activity levels in patient and control groups; a statistically significant difference was detected between groups, in terms of MET scores of the metabolic activity assessment with IPAQ-SF (Table 6). Similarly, there was also a significant difference between the groups in the scoring of "avoidance of movement questionnaire" prepared for this study.

A correlation was not detected between ICIQ-SF, and IPAQSF scores $(r=-0.148, p=0.614,95 \% \mathrm{Cl})$. A significant positive correlation was found between ICIQ-SF and the "avoidance of movement questionnaire" survey scores ( $r=0.444$, $\mathrm{p}=0.04,95 \% \mathrm{Cl}$ ) (Fig. 2).
Table 6. Intergroup comparisons as for physical activity

\begin{tabular}{lccc}
\hline Group & Median & Min-Max & $\mathbf{p}^{*}$ \\
\hline $\begin{array}{l}\text { IPAQ-SF (MET) } \\
\quad \text { Patient }\end{array}$ & 697 & $49-2400$ & 0.001 \\
$\quad$ Control & 2100 & $580-2900$ & \\
Avoidance of movement & & & \\
questionnaire & & & \\
$\quad$ Patient & 21.5 & $18-30$ & 0.004 \\
Control & 16 & $16-17$ & \\
\hline
\end{tabular}

*Mann-Whitney U test.

When the correlation between urinary incontinence and physical activity level was examined, no significant relationship was found between the pad test and IPAQ-SF $(r=0.017, p=0.954,95 \% \mathrm{Cl})$. No significant correlation was found between the ICIQ-SF and the "Avoidance of Movement Questionnaire" $(r=0.014, p=0.962,95 \% \mathrm{Cl})$.

\section{iii. Quality of life scale assessments between the patient, and the control groups}

A significant difference between the two groups in all quality of life subscale categories except for physical role limitation (Table 7) was observed in the evaluation of the quality of life of the patient and control groups.

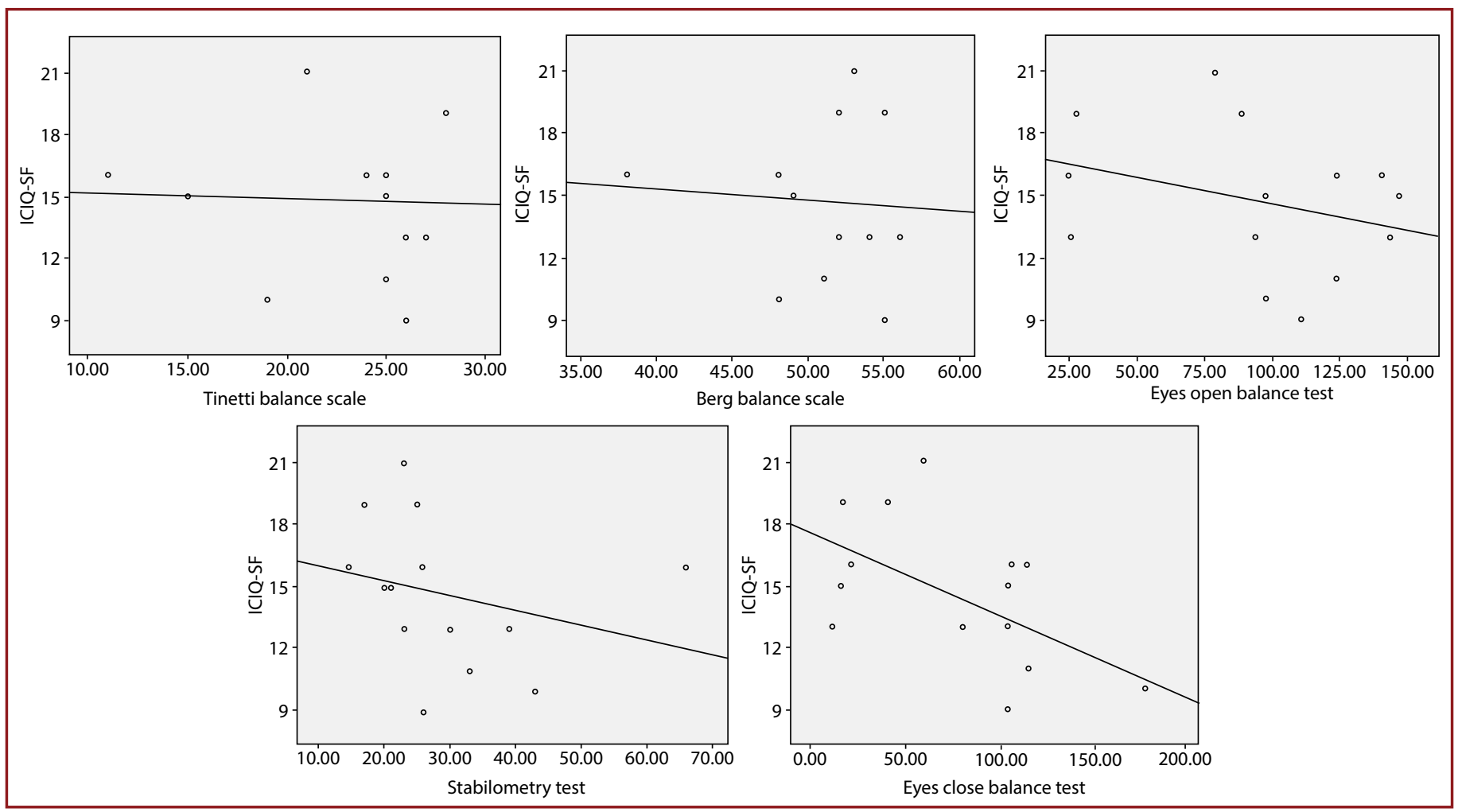

Figure 1. Correlation analysis between urinary incontinence severity (ICIQ-SF) and balance tests. 


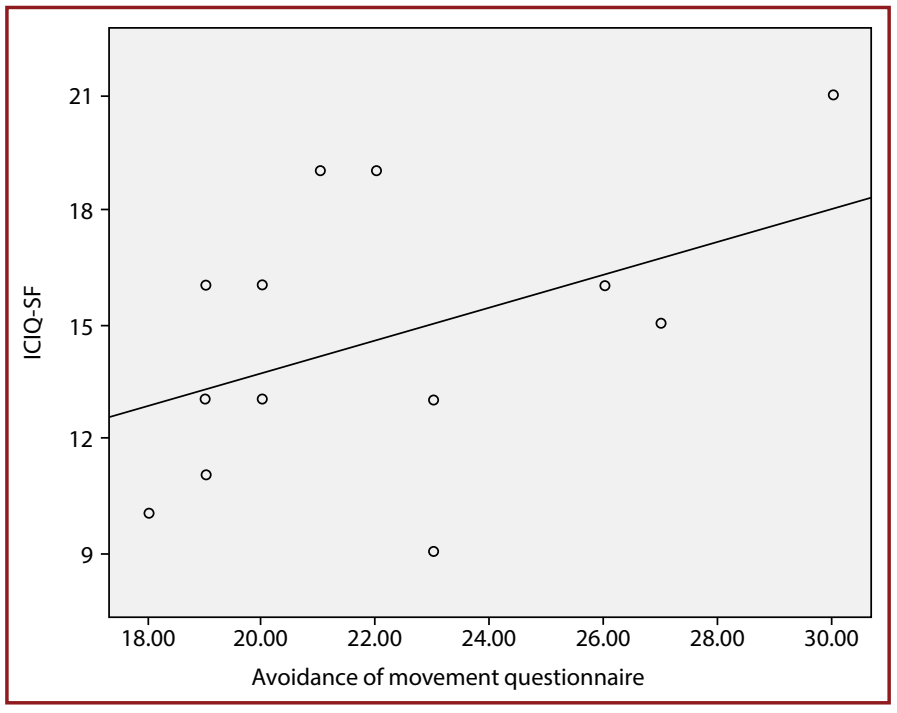

Figure 2. Correlation analysis between urinary incontinence severity (ICIQ-SF) and Avoidance of movement questionnaire.

Table 7. Comparative assessment of both groups in terms of quality of life scale scores

\begin{tabular}{|c|c|c|c|}
\hline Group & Median & Min-Max & $\mathbf{p}^{*}$ \\
\hline \multicolumn{4}{|c|}{ Physical functioning } \\
\hline Patient & 71.03 & $60-90$ & 0.005 \\
\hline Control & 80 & $70-90$ & \\
\hline \multicolumn{4}{|c|}{ Physical role limitation } \\
\hline Patient & 96 & $52-100$ & 0.51 \\
\hline Control & 100 & $88-100$ & \\
\hline \multicolumn{4}{|l|}{ Pain } \\
\hline Patient & 59 & $54-62$ & 0.01 \\
\hline Control & 64 & $58-70$ & \\
\hline \multicolumn{4}{|c|}{ General health perception } \\
\hline Patient & 50 & $35-60$ & 0.01 \\
\hline Control & 65 & $60-70$ & \\
\hline \multicolumn{4}{|c|}{ Energy Vitality } \\
\hline Patient & 24 & $20-76$ & 0.01 \\
\hline Control & 76 & $52-80$ & \\
\hline \multicolumn{4}{|c|}{ Social functioning } \\
\hline Patient & 56 & $38-88$ & 0.01 \\
\hline Control & 78 & $74-88$ & \\
\hline \multicolumn{4}{|c|}{ Emotional role limitation } \\
\hline Patient & 66 & $33-100$ & 0.03 \\
\hline Control & 100 & $66-100$ & \\
\hline \multicolumn{4}{|c|}{ Mental health } \\
\hline Patient & 47.5 & $40-55$ & 0.01 \\
\hline Control & 70 & $55-75$ & \\
\hline
\end{tabular}

*Mann- Whitney U testi.

\section{Discussion}

This study is one of the rare studies investigating the relationship between urinary incontinence and balance/stability and physical activity. As a result of our study, it was found that physical activity was significantly restricted in patients with urinary incontinence compared to control subjects. A statistically significant difference was found between urinary incontinent and control patients as for "avoidance of movement" questionnaire that we designed for this study.

It is known that regular physical activity plays an important role in healthy life, prevention of health problems and decreases premature mortality rates ${ }^{[5]}$. Physical activity has been shown to be associated with many factors as well as urinary incontinence, leading to a decrease in physical activity $[2,6]$. In our study, it was revealed that the physical activity levels of the incontinent patients decreased and these patients refrained from activity.

Generally a correlation was not found between severity levels of subjective and objective urinary incontinence and physical activity levels. The literature information on this subject is debatable. In a study, Brown and Miller demonstrated that as the amount of urinary leakage increases, physical activity levels decrease ${ }^{[7]}$. In some studies, it has been reported that there is no correlation between severity of urinary incontinence and physical activity level ${ }^{[8,9]}$.

It has been thought that our study results may be related to exclusion of very old population from the study, and in compliance with greater number of exclusion criteria only 2 patients had urine leakage more than $100 \mathrm{~g}$ (very severe incontinence) within 24 hours, and some patients' continuing their regular exercises by taking measures (protective pad) despite presence of some restriction.

It is known that obesity is more often seen in physically inactive people ${ }^{[10]}$. In a study evaluating physical activity in patients with $O A B$, multivariate analysis showed that physical activity was restricted in those with $O A B$, and $O A B$ was associated with increased $\mathrm{BMI}$ and comorbidity ${ }^{[11]}$. In another study investigating the relationship between overactive bladder and stress urinary incontinence (SUI) and BMI, it was reported that both diseases may be associated with unusual metabolic status and increased BMI ${ }^{[12]}$.

However, the causal relationship between urinary incontinence and obesity is not yet clear. Obesity and metabolic syndrome itself is known to lead to urinary incontinence [13]. Further studies are needed to explain this relationship.

There is no consensus in the literature about whether treatment of overactive bladder and urinary incontinence increases physical activity. In a study where changes in physical activity were investigated secondary to overactive bladder treatment, a significant increase in physical activity with $O A B$ symptom control was reported [14]. Stach-Lempinen et al. ${ }^{[15]}$ reported no difference in the 
post-treatment physical activity changes when compared with pre-treatment status in patients with stress urinary incontinence.

In another study evaluating pre and postoperative physical activity of the patients who had undergone midurethral sling application due to stress urinary incontinence, postoperative increase in physical activity levels of the patients was reported ${ }^{[3]}$. In our study, postoperative physical activity levels of the patients were not evaluated.

In this study, it was determined that urinary incontinence causes decrease in quality of life scores in all domains except physical role limitation. It has been shown that urge incontinence (UI) more frequently keeps the patients away from participating in every day life, and recreational activities, however if the location of the toilet is known, then patients continue participating in activities. It has been reported that SUI can lead to humiliation and physical role limitation due to wetness, and it has been also determined that SUI affects quality of life adversely both from functional, and psychologic aspects ${ }^{[16]}$.

Potential reasons for not observing a significant difference in the physical role limitation in our study may be that physical activities of the patients may be already limited before the onset of incontinence problem, although the quality of life (QoL) scales evaluated a 4-week period, symptoms of the patients might start long before application of QoL measurement instruments.

In a study conducted in the Netherlands, impaired quality of life and limited physical activity were reported in a young (20-45 years) group of patients with urinary incontinence or overactive bladder ${ }^{[17]}$. Indeed, the main cause of application of urinary incontinence patients for treatment, appears to be impaired quality of life ${ }^{[18]}$.

One of the important features of our study was evaluation of the relationship between urinary incontinence and postural balance. It is known that elderly people with urinary incontinence are at increased risk of falling from a height and its associated complications ${ }^{[19]}$. However, it is not yet clarified whether the increased risk of falling from a height in these patients is related to frequent movements caused by urgent need to urinate and urine leakage or postural balance and gait disorders which may be caused by urinary incontinence.

Current literature data suggest that control of continence, postural stability, and gait are realized from similar localizations in the central nervous system, and that disorders of these functions may have a common pathophysiology [4].

A significant difference was found between the patients in our study group and the control group in terms of all balance measurements and balance test results except for the stability test. However, there was no significant correlation between ICIQ-SF score and physical examination tests and balance measurements except "eyes closed balance test". In a study by Smith et al. ${ }^{[20]}$ patients with stress urinary incontinence were found to have impaired ability to maintain postural balance compared to the control group.

In patients with urinary incontinence, difficulties may arise in postural control due to increased body and pelvic floor muscle activity ${ }^{[21]}$.

Possible mechanisms that may suggestively lead to impaired balance in patients with urinary incontinence include: restricted bodily movements for postural control of the body affected by rigidity of pelvic floor and trunk muscles, reduction of proprioceptive acuity in the trunk muscles (stronger contraction of other periarticular muscles); displacement of central trunk pressure due to urine leakage, reduced balance function due to cognitive impairment, and resultant.postural disorganization [22-24].

Strengths of our study include evaluation of the urinary incontinence from different perspectives such as physical activity, balance and quality of life, evaluating the relation between urinary incontinence, balance and physical activity level using objective and subjective findings which has been rarely studied in the literature, and scope of exclusion criteria was kept at a maximum and target population was selected among patients with homogenous characteristics as much as possible.

The main limitations of our study can be summarized as follows. Both groups contained scarce number of patients, inability to assess gait pattern except for physical activity. Although BMI affected balance and movement, proper sampling was not performed between the control and the patient groups. Besides, despite evaluation of incontinence, overactive bladder and stress urinary incontinence have different pathophysiological mechanisms and changes in target criteria after urinary incontinence therapy were not assessed.

Physical activity of the patients with urinary incontinence is restricted and quality of life is reduced compared to control subjects who have not lower urinary tract system complaints. Compared to the control subjects, significant deterioration was detected in the balance examinations and the measurement results in women who had urinary incontinence without any other illness that could lead to impaired balance. Besides, a significant correlation between the objective and subjective measures of urinary 
incontinence and balance scales was not detected. There is a need for further studies involving greater number of patient groups.

Ethics Committee Approval: The approval of the local Ethics Committee was obtained.

Peer-review: Externally peer-reviewed.

Authorship Contributions: Concept: A.T., D.K., U.B.; Design: A.T., D.K., E.V.K.; Data Collection or Processing: A.T., A.B., E.V.K.; Analysis or Interpretation: A.T., A.B., D.K., U.B.; Literature Search: A.T., B.Ş.; Writing: A.T., D.K., B.Ş., U.B.

Conflict of Interest: None declared.

Financial Disclosure: The authors declared that this study received no financial support.

\section{References}

1. Barning F, Abarin T. Assessing the Causality Factors in the Association between (Abdominal) Obesity and Physical Activity among the Newfoundland Population-A Mendelian Randomization Analysis. Genet Epigenet 2016;8:15-24. [CrossRef]

2. Nygaard I, Girts T, Fultz NH, Kinchen K, Pohl G, Sternfeld B. Is urinary incontinence a barrier to exercise in women? Obstet Gynecol 2005;106:307-14. [CrossRef]

3. Sung VW, Kassis N, Raker CA. Improvements in physical activity and functioning after undergoing midurethral sling procedure for urinary incontinence. Obstet Gynecol 2012;120:57380. [CrossRef]

4. Booth J, Paul L, Rafferty D, Macinnes C. The relationship between urinary bladder control and gait in women. Neurourol Urodyn 2013;32:43-7. [CrossRef]

5. Carlson SA, Fulton JE, Schoenborn CA, Loustalot F. Trend and prevalence estimates based on the 2008 Physical Activity Guidelines for Americans. Am J Prev Med 2010;39:305-13. [CrossRef]

6. DeLancey JO, Nygaard I. Exercise-associated urinary incontinence. JAMA 1991;265:514. [CrossRef]

7. Brown WJ, Miller YD. Too wet to exercise? Leaking urine as a barrier to physical activity in women. J Sci Med Sport 2001;4:373-8. [CrossRef]

8. Burgio KL, Matthews KA, Engel BT. Prevalence, incidence and correlates of urinary incontinence in healthy, middle-aged women. J Urol 1991;146:1255-9. [CrossRef]

9. Alling Møller L, Lose $G$, Jørgensen T. Risk factors for lower urinary tract symptoms in women 40 to 60 years of age. Obstet Gynecol 2000;96:446-51. [CrossRef]

10. Lee J, Song J, Hootman JM, Semanik PA, Chang RW, Sharma L, et al. Obesity and other modifiable factors for physical inactiv- ity measured by accelerometer in adults with knee osteoarthritis. Arthritis Care Res (Hoboken) 2013;65:53-61. [CrossRef]

11. Coyne KS, Sexton CC, Clemens JQ, Thompson CL, Chen $\mathrm{Cl}$, Bavendam T, et al. The impact of OAB on physical activity in the United States: results from OAB-POLL. Urology 2013;82:799806. [CrossRef]

12. Teleman PM, Lidfeldt J, Nerbrand C, Samsioe G, Mattiasson A; WHILA study group. Overactive bladder: prevalence, risk factors and relation to stress incontinence in middle-aged women. BJOG 2004;111:600-4. [CrossRef]

13. Krhut J, Martan A, Zachoval R, Hanuš T, Švabík K, Zvara P. Impact of body mass index on treatment efficacy of mirabegron for overactive bladder in females. Eur J Obstet Gynecol Reprod Biol. 2016;196:64-8. [CrossRef]

14. Chu CM, Harvie HS, Smith AL, Arya LA, Andy UU. The Impact of Treatment of Overactive Bladder on Physical Activity Limitations. J Womens Health (Larchmt) 2016;25:801-5. [CrossRef]

15. Stach-Lempinen $B$, Nygård CH, Laippala P, Metsänoja R, Kujansuu $E$. Is physical activity influenced by urinary incontinence? BJOG 2004;111:475-80. [CrossRef]

16. Brazell HD, O'Sullivan DM, Lasala CA. Does the impact of urinary incontinence on quality of life differ based on age? Int Urogynecol J 2013;24:2077-80. [CrossRef]

17. van der Vaart $\mathrm{CH}$, de Leeuw JR, Roovers JP, Heintz AP. The effect of urinary incontinence and overactive bladder symptoms on quality of life in young women. BJU Int 2002;90:544-9. [CrossRef]

18. Huang AJ, Brown JS, Kanaya AM, Creasman JM, Ragins AI, Van Den Eeden SK, et al. Quality-of-life impact and treatment of urinary incontinence in ethnically diverse older women. Arch Intern Med 2006;166:2000-6. [CrossRef]

19. Chiarelli PE, Mackenzie LA, Osmotherly PG. Urinary incontinence is associated with an increase in falls: a systematic review. Aust J Physiother 2009;55:89-95. [CrossRef]

20. Smith MD, Coppieters MW, Hodges PW. Is balance different in women with and without stress urinary incontinence? Neurourol Urodyn 2008;27:71-8. [CrossRef]

21. Smith MD, Coppieters MW, Hodges PW. Postural response of the pelvic floor and abdominal muscles in women with and without incontinence. Neurourol Urodyn 2007;26:377-85. [CrossRef]

22. Pellecchia GL. Postural sway increases with attentional demands of concurrent cognitive task. Gait Posture 2003;18:2934. [CrossRef]

23. Taylor JL, McCloskey DI. Detection of slow movements imposed at the elbow during active flexion in man. J Physiol 1992;457:503-13. [CrossRef]

24. Wise AK, Gregory JE, Proske U. Detection of movements of the human forearm during and after co-contractions of muscles acting at the elbow joint. J Physiol 1998;508:325-30. [CrossRef] 